\title{
ATENÇÃo QUALIFICADA AO PRÉ-NATAL E PUERPÉRIO: UMA INTERVENÇÃo EM SERVIÇO NA ATENÇÃO BÁSICA
}

\section{ENHANCED CARE TO PRENATAL AND PUERPERIUM: AN INTERVENTION IN A SERVICE OF BASIC CARE}

\author{
Paula Lamperth Vargas, ${ }^{1}$ Sidneia Tessmer Casarin, ${ }^{2}$ Simone Coelho Amestoy, ${ }^{2}$ Seiko Nomiyama, ${ }^{2}$ Teila \\ Ceolin, ${ }^{2}$ Andrea Gonçalves Bandeira ${ }^{3}$ \\ ${ }^{1}$ Prefeitura de Vista Gaúcha/Vista Gaúcha/Brasil. ${ }^{2}$ Universidade Federal de Pelotas/Pelotas/Brasil. ${ }^{3}$ Universidade Federal do Rio \\ Grande do Sul/Porto Alegre/Brasil. \\ Autor correspondente: Sidneia Tessmer Casarin e-mail: stcasarin@gmail.com
}

\section{EDITORES}

Thiago Gomes Heck

(Unijuí-Brasil)

Adriane Cristina Bernat Kolankiewicz

(Unijuí-Brasil)

\section{EDITORES DE ÁREA}

Educação \& Saúde

Eva Teresinha de Oliveira Boff

(Unijuí-Brasil)

Fisioterapia \& Saúde

Eliane Roseli Winkelmann

(Unijuí-Brasil)

Ciências Farmacêuticas \& Saúde

Marilei Uecker Pletsch

(Unijuí-Brasil)

Nutrição \& Saúde

Lígia Beatriz Bento Franz

(Unijuí-Brasil)

Nadia Oliveira

(Unipampa-Brasil)

Ingrid Perry

(UNESC-Brasil)

Enfermagem e suas contribuições para

a prática

Adriane Cristina Kolankiewicz

(Unijuí-Brasil)

Crhis de Brum

(UFFS-Brasil)

Neila de Souza

(UFSM-Brasil)

Exercício Físico \& Saúde

Thiago Gomes Heck

(Unijuí-Brasil)

Anderson Zampier Ulbrich

(UFPR)

Editora Unijuí

Universidade Regional do Noroeste do

Estado do Rio Grande do Sul (Unijuí)

\section{RESUMO}

Objetivo: este texto objetivou descrever e analisar a experiência do desenvolvimento de um projeto de intervenção para a qualificação da assistência à gestante e à puérpera em uma unidade de Saúde da Família de um município do interior do Rio Grande do Sul. Métodos: trata-se de um relato de experiência que ocorreu durante 16 semanas, entre os meses de março a junho de 2012, nos quais foram instituídas ações direcionadas à organização e gestão do serviço, ao monitoramento e avaliação, à qualificação da prática clínica e ao engajamento público em uma Equipe de Saúde da Família. Resultados: as ações permitiram identificar o atendimento de 21 mulheres (gestantes e puérperas), obtendo-se $100 \%$ da cobertura de atendimento e $100 \%$ de adesão antes dos 120 dias de gravidez, assim como a qualificação da prática clínica e ampliação das atividades de promoção da saúde e dos registros de atendimento. Conclusão: entende-se que a experiência foi significativa, pois contribuiu para melhorar a organização do serviço e o alcance de resultados efetivos relacionados à assistência ao pré-natal e puerpério.

Palavras-chave: Atenção primária à saúde. Estratégia Saúde da Família. Pré-natal. Puerpério. Saúde da mulher. Enfermagem.

Submetido em: 30/9/2015

Aceito em: 22/6/2016 


\section{Revista}

\section{Contexto}

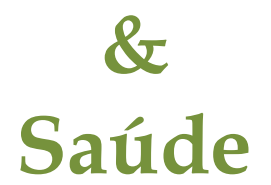

Volume 16

Número 31

2016

ISSN 2176-7114
A Revista Contexto \& Saúde é um periódico do Departamento de Ciências da Vida da Universidade Regional do Noroeste do Estado do Rio Grande do Sul (Unijuí). É um periódico semestral que tem por objetivo a divulgação da produção técnico-científica de temas relacionados à área de Ciências da Saúde.

O escopo da revista abrange a divulgação de resultados de pesquisa que contemplem avanços no processo saúde-doençacuidado e no conhecimento e aplicabilidade de novos processos químicos e biológicos em saúde.

Neste periódico, entende-se que a publicação de estudos com os aspectos epidemiológicos, assistenciais e educacionais em saúde, experimentais e aplicados é uma forma a subsidiar e qualificar a atenção à saúde de modo interdisciplinar.

\begin{abstract}
Objective: it was aimed describe and evaluate the experience of development of an intervention project for the enhancement of care for pregnant and puerperal women in a basic health unit of a municipality from the countryside of Rio Grande do Sul. Methodology: This is an experience report that occurred during 16 weeks, between the months of March and June 2012, when they implemented actions targeted to the organization and management of the service, monitoring and assessment, enhancement of clinical practice and public engagement. Results: 21 women were served (pregnant and puerperal women), thus obtaining $100 \%$ of coverage of health care and $100 \%$ of adherence before 120 days of pregnancy, as well as the enhancement of clinical practice and expansion of health promotion activities and care records. Conclusion: it is understood that the experience was significant, since it has contributed to improve the organization of service and the achievement of effective results related to the care provided to prenatal and puerperium.
\end{abstract}

Keywords: Primary health. Family health strategy. Prenatal care. Postpartum. Women's health. Nursing. 


\section{INTRODUÇÃO}

A assistência ao pré-natal e ao puerpério com qualidade e de forma humanizada é fundamental para a saúde materna e neonatal. O acompanhamento da gravidez, parto e puerpério pelos serviços de saúde, devem ser momentos de aprendizagem para a mulher e sua família, permitindo detectar as alterações que podem colocar em risco a vida da mãe e da criança. Entre os princípios da Rede Cegonha, instituída no Sistema Único de Saúde em 2011, estão à garantia do acolhimento à mulher no período gravídico-puerperal, com avaliação e classificação de risco e vulnerabilidade, ampliação do acesso e melhoria da qualidade do pré-natal, parto e puerpério e a atenção à saúde da criança (BRASIL, 2011). Sendo assim, para garantir uma assistência qualificada à gestante e à puérpera, é necessária a estruturação dos serviços de saúde, principalmente os de atenção básica. Diante do exposto, cabe aos profissionais envolvidos com a atenção pré-natal e puerperal acolher a mulher e a criança com dignidade, assegurando a eles o papel de protagonistas nos serviços de saúde.

A assistência pré-natal e puerperal de qualidade está associada à redução da morbimortalidade materno-infantil. Iniciativas, neste sentido, vieram do Ministério da Saúde e, dentre elas, pode-se citar o Programa de Humanização do Parto e Nascimento (PHPN), sendo este o primeiro modelo que normatizou a assistência ao pré-natal no Brasil. O PHPN teve início no ano 2000 e visava a "assegurar a melhoria do acesso, da cobertura e da qualidade do acompanhamento pré-natal, da assistência ao parto e puerpério às gestantes e ao recém-nascido, na perspectiva dos direitos de cidadania" (BRASIL, 2002, p. 5).

O programa, além de determinar o número de consultas e a idade gestacional de ingresso mais apropriada para garantir a qualidade da assistência, também estabeleceu quais exames laboratoriais e quais ações de educação em saúde eram prioritárias (ANVERSA et al., 2012; SAAVEDRA; CESAR, 2015).

A Estratégia de Saúde da Família (ESF) iniciou como programa governamental em 1994. Em 2006 passou a ser uma estratégia para reorientar a atenção primária no Brasil; trabalha com a perspectiva multiprofissional de saúde em um território adscrito. Na literatura há registros de que a assistência pré-natal realizada na ESF tem indicadores de cobertura semelhantes aos proporcionados pelo setor privado, sendo superiores os indicadores relacionados à sorologia para sífilis, anti-HIV, citopatológico para colo uterino, suplementação com sulfato ferroso e vacinação antitetânica (CESAR et al., 2012).

Diante da importância do trabalho da equipe multiprofissional, este estudo teve como objetivo descrever e analisar a experiência do desenvolvimento de um projeto de intervenção para a qualificação da assistência à gestante e à puérpera em uma unidade de Saúde da Família de um município do interior do Rio Grande do Sul.

\section{METODOLOGIA}

Este artigo caracteriza-se como relato de experiência a partir da aplicação de uma intervenção em serviço, ocorrida durante 16 semanas entre os meses de março e junho de 2012.

O projeto de intervenção foi construído durante as atividades da Especialização em Saúde da Família Unasus/Ufpel - (modalidade EaD), após ser realizada uma análise situacional na Unidade Básica de Saúde (UBS). A coordenação do projeto na UBS foi da enfermeira da equipe. A logística para o desenvolvimento das ações direcionadas às gestantes e puérperas incluiu a capacitação da prática clínica por meio de encontros e oficinas com todos os profissionais da equipe. Nos encontros foi revisado o Caderno da Atenção Básica $n^{\circ} 32$ que trata do pré-natal de baixo risco (BRASIL, 2013) e também abordada a importância dos registros completos nos prontuários e nos formulários do Sisprenatal e Rede Cegonha. Nas oficinas foram apresentadas as planilhas de acompanhamento dos indicadores que seriam analisados durante a intervenção. Essas planilhas foram disponibilizadas pela coordenação do curso de especialização no Microsoft Excel. 
A UBS, que foi palco do projeto de intervenção, está localizada na área urbana de um município do interior do Rio Grande do Sul, o qual possui 2.759 habitantes, e está situado na região Noroeste do Estado. Na UBS trabalham profissionais que compõem uma equipe mínima da ESF e uma equipe de saúde bucal. Mesmo estando localizada na área urbana, a UBS abrange, em sua maior parte, as famílias residentes na zona rural, totalizando, assim, 926 famílias. A faixa etária da maioria da população está compreendida entre 20 e 39 anos. A estrutura física da UBS é ampla e foi inaugurada em outubro de 2010. É composta por sala de acolhimento, sala de espera, sala de vacinas, ambulatório, consultório odontológico, sala de coleta de exame preventivo (citopatologia para colo uterino), consultório médico e sala de reuniões.

Durante o período da intervenção foram atendidas 21 mulheres entre gestantes e puérperas. No $1^{\circ}$ mês foram 17 , no $2^{\circ}$ mês, 13 , no $3^{\circ}$ mês, 12 e no $4^{\circ}$ mês, 14 .

Após a construção do projeto, as ações desenvolvidas na intervenção englobaram quatro eixos temáticos, sendo três da área da saúde coletiva (monitoramento e avaliação; organização e gestão do serviço e engajamento público) e um da área clínica (qualificação da prática clínica), de acordo com o projeto pedagógico do curso.

Cabe salientar que o plano de intervenção integra o projeto Qualificação das Ações Programáticas na Atenção Básica, o qual respeita os princípios da bioética e a Resolução 196/96 do Conselho Nacional de Saúde vigente na época, tendo sido aprovado no Comitê de Ética da Faculdade de Medicina da Universidade Federal de Pelotas (Ufpel) mediante o parecer $\mathrm{n}^{\mathrm{o}} 15 / 12$.

\section{DESENVOLVIMENTO DA PROPOSTA E RESULTADOS}

Foram desenvolvidas ações visando à ampliação da cobertura pré-natal e puerpério da UBS; melhoria da adesão ao pré-natal e puerpério; melhoria da qualidade da assistência ao pré-natal e puerpério; melhoria e qualificação dos registros das informações; realização do mapeamento das gestantes de risco; e realização de atividades de promoção da saúde das gestantes e puérperas. As ações que foram previstas durante o projeto foram desenvolvidas na íntegra, sendo especificadas a seguir.

Para que um projeto de intervenção possa ser executado com sucesso, todos os profissionais precisam se envolver e definir suas atribuições. Diante disso, foram desenvolvidas ações no sentido de qualificar a prática clínica de todos os trabalhadores da UBS. Assim, foram realizados os encontros de capacitação, para que a equipe tivesse conhecimento do Caderno de Atenção Básica no 32 (BRASIL, 2013), o qual foi utilizado como protocolo de atendimento à gestante puérpera, e também para que estivessem sensibilizados a identificar prováveis gestantes. Nas capacitações também foram abordados temas referentes ao período de pré-natal e puerpério, como as modificações gravídicas, a importância do acompanhamento de pré-natal, a amamentação, os cuidados nutricionais, a vacinação, os cuidados com o corpo durante a gravidez e no pós-parto, os cuidados com o bebê, entre outras orientações repassadas às gestantes durante a realização de visitas domiciliares. No decorrer das capacitações percebeu-se o ensejo da equipe em realizar educação permanente.

Foram efetivados o cadastramento e a avaliação de todas as gestantes e puérperas residentes na área de abrangência da UBS, assim como a avaliação periódica da cobertura de pré-natal e puerpério e o monitoramento do porcentual de gestantes que ingressou no programa no primeiro trimestre de gestação. Ao final de cada mês realizou-se a avaliação do número de consultas de pré-natal de cada gestante, e novas metas de atendimentos foram definidas. 
Para melhorar a adesão ao pré-natal e puerpério ocorreram avaliações periódicas do acompanhamento de prénatal e a busca ativa, quando era identificada alguma gestante faltosa às consultas, exames ou vacinas. Foram discutidas com a equipe questões referentes ao acolhimento e quanto à organização do atendimento às gestantes para as consultas médicas, odontológicas e de enfermagem, sendo definido que o mesmo ocorreria em um dia do mês específico, porém se houvesse necessidade de atendimento, como alguma intercorrência, essas teriam prioridade em outro horário também.

Também foram monitoradas as questões referentes à vacinação na gestação, à solicitação e à realização dos exames preconizados, assim como a suplementação com sulfato ferroso e ácido fólico, os quais foram garantidos, pelo município, a todas as gestantes. Com a finalidade de melhorar e qualificar os registros das informações referentes aos atendimentos de pré-natal e puerpério, os prontuários foram revisados e avaliados com o registro adequado, primando pelo correto preenchimento dos formulários do Sisprenatal e do cartão da gestante.

Sabe-se que o prontuário é um direito do usuário do sistema de saúde. O preenchimento dos formulários correspondentes às informações do pré-natal e puerpério é essencial para a alimentação do sistema de informação próprio (Sisprenatal) e também indispensável para possibilitar o monitoramento dos indicadores do pré-natal e puerpério. O cartão da gestante é um instrumento importante que revela toda a trajetória da usuária durante seu processo gestacional. É um instrumento de referência tanto para os profissionais pré-natalistas quanto para os que irão atender o parto e também fonte de dados para outros sistemas de informação, como o dos nascidos vivos (Sinasc) (SANTOS NETO et al., 2012).

Atentou-se ainda para a necessidade de mapear as gestantes de risco e, por este motivo, a avaliação do risco gestacional foi realizada mês a mês. Desta forma, organizaram-se visitas domiciliares para as gestantes que apresentavam algum risco à saúde. Atividades de promoção da saúde no pré-natal também foram incluídas na intervenção. Para tanto, foram realizadas reuniões com as gestantes, nas quais abordou-se a importância do ingresso precoce no pré-natal, além de orientações não somente a elas, mas também aos seus familiares sobre os cuidados no puerpério e com o recém-nascido. Também ocorreram orientações sobre fatores de risco, cuidados com a alimentação, álcool e outras drogas, higiene bucal e aleitamento materno.

As equipes atuantes na atenção básica têm a responsabilidade pela população de sua área adscrita, mesmo quando o usuário opta ou precisa acessar outros serviços de saúde (BRASIL, 2012). Assim, as gestantes e puérperas foram acompanhadas durante o período, mas nem todas fizeram consultas de pré-natal na Unidade de Saúde, contudo foram visitadas pelos agentes comunitários de saúde e pela enfermeira. Entre as 21 gestantes, 3 optaram por realizar acompanhamento no serviço privado.

Antes do início da intervenção a cobertura de acompanhamento de pré-natal era, em média, de 70\%. Após a intervenção, todas as gestantes e puérperas, fazendo pré-natal na Unidade de Saúde ou não, passaram a ser acompanhadas por algum dos membros da equipe de saúde, principalmente pelo agente comunitário de saúde e pela enfermeira. Após a intervenção, ficou incorporada à rotina do serviço a determinação de que para cada gestante que não está comparecendo à consulta de pré-natal será realizada busca ativa pelo agente comunitário de saúde. Isto é o impacto da intervenção no serviço, ou seja, resultado das ações realizadas.

Visando a promover a saúde na comunidade e estimular o engajamento público, foram realizadas reuniões com a comunidade quando foi esclarecida a prioridade no atendimento às gestantes e puérperas, bem como colocado avisos nas rádios locais.

Com o intuito de analisar os resultados atingidos durante as 16 semanas de intervenção, foram traçadas metas de acordo com os objetivos propostos pelo projeto de intervenção. Essas metas foram quantificadas em alguns 
indicadores relacionados com a cobertura e com a qualidade dos serviços de pré-natal e puerpério. Sendo assim, descreve-se, a seguir, os resultados que foram mensurados.

No projeto, a meta de ampliação da cobertura de atendimento das gestantes e puérperas na UBS foi estipulada em 85\%. Para o monitoramento dessa meta adotou-se como indicador a proporção de gestantes e puérperas moradoras no território e cadastradas no programa. Assim, já no primeiro mês foi possível cadastrar todas as gestantes e puérperas no serviço, mantendo-se $100 \%$ de cobertura nos demais meses em que foi desenvolvido o projeto.

O início precoce do pré-natal é essencial para a qualidade da assistência (BRASIL, 2013), portanto, para garantir captação das gestantes antes dos 120 dias de gestação, foi monitorada a proporção de gestantes que iniciou o pré-natal antes deste período. No primeiro mês obteve-se 94,1\% das gestantes com início precoce no pré-natal e, nos meses subsequentes, obteve-se $100 \%$ com início no período recomendado. O parâmetro de 120 dias de gestação como início precoce da assistência pré-natal foi definido pelo PHPN (BRASIL, 2012) em 2002, mas, a partir de 2012, o Ministério da Saúde recomenda que o pré-natal seja iniciado até a $12^{\circ}$ semana de gravidez (MENDOZA-SASSI et al., 2011), recomendação que surgiu após a finalização das atividades do projeto.

Para captar $100 \%$ das gestantes da área que não realizavam pré-natal na UBS e em nenhum outro serviço, foi estipulado como indicador a proporção de gestantes residentes na área e sem atendimento. Sendo assim, em todos os meses da intervenção nenhuma gestante ficou sem assistência pré-natal. Nem todas, porém, seguiram o acompanhamento na UBS, optando pela assistência privada, com três gestantes no primeiro mês; duas no segundo; uma no terceiro e nenhuma no quarto mês da intervenção. Para essas gestantes foi assegurado o acompanhamento do ACS e da enfermeira; assim, seus nomes seguiram no cadastro da UBS.

Com vistas a recuperar as gestantes e puérperas faltosas ao pré-natal e puerpério, utilizou-se o indicador "proporção de mulheres com atraso no atendimento de acordo com os períodos preconizados pelo protocolo". Desde o primeiro mês da intervenção não foram identificadas gestantes ou puérperas com mais de 15 dias em atraso. Quando detectada a ausência de alguma gestante ou puérpera às consultas, os agentes comunitários eram acionados para realizar a busca ativa. Desta forma, nenhuma mulher ficou em atraso com o atendimento preconizado e todas foram recuperadas. A busca ativa (BRASIL, 2013) das gestantes faltosas ao pré-natal e das puérperas faltosas à primeira consulta pós-parto, é uma ação que deve ser garantida pelos serviços de saúde.

O diagnóstico e a prevenção dos cânceres de colo uterino e mama são ações que devem ser avaliadas pelos profissionais de saúde quando prestam assistência pré-natal (BRASIL, 2013). Para poder acompanhar se as ações de rastreio do câncer ginecológico estavam ocorrendo conforme o preconizado, analisou-se a proporção de gestantes com exame ginecológico em dia de acordo com o protocolo. No primeiro mês de intervenção, apenas 35,3\% das gestantes atendidas estavam com o exame ginecológico realizado conforme o preconizado. Já nos meses subsequentes, todas as gestantes foram assistidas.

O exame clínico das mamas na gestante, além de detectar anormalidades com vistas à prevenção do câncer de mama, também é uma oportunidade importante para que o profissional de saúde oriente sobre a amamentação e os cuidados com a mama neste período (BRASIL, 2013). No primeiro mês da intervenção apenas uma gestante teve suas mamas examinadas. Por meio do projeto e com monitoramento contínuo, nos meses subsequentes todas as gestantes atendidas tiveram suas mamas examinadas. 
O Ministério da Saúde recomenda que a consulta de puerpério ocorra até o $42^{\circ}$ dia pós-parto (BRASIL, 2013). Sendo assim, a revisão puerperal, até o $42^{\circ}$ dia pós-parto, também foi alvo da intervenção. No primeiro mês de intervenção existiam duas mulheres no período pós-parto, contudo nenhuma delas realizou a revisão no prazo preconizado. Desempenhando as atividades previstas no projeto e realizando o monitoramento dos partos, no segundo mês o indicador já apresentou melhora significativa, posto que das três puérperas, duas realizaram a revisão dentro do prazo estipulado. Assim, no terceiro e quarto meses o índice chegou a 100\%, uma vez que no terceiro mês havia uma puérpera e no quarto mês mais duas.

Há orientação pelo Ministério da Saúde para prescrição de suplementação de sulfato ferroso e ácido fólico para todas as gestantes com a finalidade de evitar os baixos níveis de hemoglobina no parto e no puerpério (BRASIL, 2013). Para poder analisar se todas as gestantes estavam recebendo a prescrição dos medicamentos, foi analisado o indicador proporção de gestantes com prescrição de suplementação de sulfato ferroso e ácido fólico. Ao longo dos quatro meses o indicador sempre chegou aos $100 \%$, ou seja, todas as gestantes receberam prescrição para suplementação de ambos os medicamentos, conforme orienta o protocolo.

Atualmente são solicitados no primeiro trimestre (ou na primeira consulta) os seguintes exames laboratoriais: hemograma; tipagem sanguínea e fator Rh; Coombs indireto (se for Rh negativo); glicemia em jejum; teste rápido de triagem para sífilis e/ou VDRL/RPR; teste rápido diagnóstico anti-HIV; Anti-HIV; toxoplasmose IgM e IgG; sorologia para hepatite B (HbsAg); urocultura + urina tipo I (sumário de urina - SU, EQU); ultrassonografia obstétrica; citopatológico de colo de útero (se for necessário); exame da secreção vaginal (se houver indicação clínica); parasitológico de fezes (se houver indicação clínica). No segundo trimestre é preconizada a realização dos seguintes exames: teste de tolerância para glicose com $75 \mathrm{~g}$, se a glicemia estiver acima de $85 \mathrm{mg} / \mathrm{dl}$ ou se houver fator de risco (realiza-se este exame preferencialmente entre a $24^{\mathrm{a}}$ e a $28^{\mathrm{a}}$ semanas de gestação) e Coombs indireto (se for Rh negativo). No terceiro trimestre: hemograma; glicemia em jejum; Coombs indireto (se for Rh negativo); VDRL; Anti-HIV; sorologia para hepatite B (HbsAg); repetição do exame de toxoplasmose se o IgG não for reagente; urocultura e urina tipo I; bacterioscopia de secreção vaginal (a partir de 37 semanas de gestação) (BRASIL, 2013).

Tendo em vista a garantia da realização dos exames laboratoriais a 100\% das gestantes, recomendados durante o período pré-natal, utilizou-se como referência o indicador "proporção de gestantes com exames laboratoriais em dia, conforme idade gestacional". O monitoramento deste indicador e a efetivação das ações do projeto, promoveram desde o primeiro mês de intervenção a oferta de exames laboratoriais a $100 \%$ das gestantes. "A realização dos exames laboratoriais durante a gestação é um período oportuno para prevenir, identificar e corrigir as anormalidades que possam afetar a gestante e seu concepto, e instituir tratamento de doenças já existentes ou que possam ocorrer durante a gestação" (ANVERSA et al., 2012, p. 797).

Também foram estipuladas metas referentes à cobertura vacinal das gestantes, a partir da análise do indicador que avaliou a proporção de gestantes com o esquema vacinal completo contra o tétano e contra a hepatite B. Em todos os meses de intervenção obteve-se $100 \%$ de cobertura. A vacinação contra o tétano é realizada com a vacina dupla adulto (dT) e está indicada na gravidez com início em qualquer idade gestacional para proteger a gestante do tétano acidental e o recém-nascido do tétano neonatal. Já em relação à vacina contra a hepatite $\mathrm{B}$, está indicada após o primeiro trimestre da gestação. Os esquemas para ambas as vacinas seguiram o que é preconizado pelo Programa Nacional de Imunização (PNI) (BRASIL, 2013).

A vacinação contra a influenza não foi monitorada com análise de indicador, mas acompanhada pelos registros nos prontuários e fichas-espelho; assim, também se registrou que $100 \%$ das gestantes foram vacinadas, uma vez que a intervenção englobou o período de campanha de vacinação contra a gripe. Esta vacina é recomendada a todas as gestantes, independente da idade gestacional, durante a campanha anual contra a influenza sazonal (BRASIL, 2013). 
Com vistas a evitar os problemas bucais mais frequentes na gestação, como a cárie, a erosão do esmalte, a gengivite, a periodontite e os problemas de mobilidade, é recomendado que as gestantes sejam avaliadas quanto a sua saúde bucal (BRASIL, 2013). Objetivando garantir esse cuidado, foi avaliado o indicador que mediu a proporção de gestantes com avaliação de saúde bucal. No primeiro mês de intervenção apenas $29,4 \%$ das gestantes tinham realizado avaliação odontológica. Já nos meses subsequentes, todas as gestantes acompanhadas realizaram a avaliação. A avaliação bucal da gestante inclui "hábitos de higiene bucal, acesso à água fluoretada e às doenças da boca. O exame bucal deve incluir dentes, gengiva, língua, palato e mucosa" (BRASIL, 2012, p. 143).

Considerando que "o período gestacional é uma fase na qual as necessidades nutricionais são elevadas, decorrentes dos ajustes fisiológicos das gestantes e de nutrientes para o crescimento fetal" (BRASIL, 2013, p. 80), visando a garantir a todas as gestantes, que fazem o pré-natal na UBS, orientação nutricional durante a gestação, foi avaliado o indicador proporção de gestantes que receberam orientação nutricional durante o prénatal. No primeiro mês 52,9\% das gestantes haviam recebido orientação nutricional, contudo, no segundo, terceiro e quarto meses, $100 \%$ delas foram orientadas.

A amamentação exclusiva é recomendada até o sexto mês de vida da criança, sendo vantajosa tanto para o bebê quanto para a mãe. A equipe de saúde tem papel importante no estímulo à prática do aleitamento materno e precisa ter incorporada essa ação já no pré-natal (BRASIL, 2013). Na intervenção, uma das metas era proporcionar informações sobre a importância do aleitamento materno a $100 \%$ das gestantes que fazem o prénatal na UBS, e foi avaliado o indicador "proporção de gestantes que receberam orientação sobre aleitamento materno". No primeiro mês apenas 41,2\% das gestantes haviam recebido orientação profissional sobre o aleitamento materno; já nos meses seguintes, $100 \%$ delas foram orientadas.

Outras atividades de promoção da saúde também foram monitoradas, como a orientação sobre os cuidados com o recém-nascido (teste do pezinho, decúbito dorsal para dormir, anticoncepção após o parto) e sobre os riscos do tabagismo e do uso de álcool e drogas na gestação. Para estas atividades foram avaliados os indicadores: proporção de gestantes que receberam orientação sobre cuidados com o recém-nascido e proporção de gestantes que receberam orientação sobre riscos do tabagismo, álcool e drogas. Em relação aos resultados, para o primeiro indicador avaliado, no primeiro mês de intervenção, 70,6\% das gestantes haviam recebido a orientação e, nos meses seguintes, todas as gestantes estavam orientadas. Para o segundo indicador, no primeiro mês, apenas 17,6\% das gestantes receberam orientação, já nos meses seguintes $100 \%$ das gestantes tinham sido orientadas.

Entende-se que o pré-natal é um momento importante para que ações educativas ocorram, não somente na unidade de saúde em sala de espera ou consultas individuais, mas também nos grupos formados com gestantes na comunidade. O importante é que as ações educativas sejam fortalecidas pela escuta qualificada, compartilhamento de experiências, trocas, fortalecimento de vínculo e acolhimento (ANVERSA et al., 2012).

Destaca-se que atenção especial deve ser disponibilizada às gestantes que apresentam maiores riscos, com o intuito de reduzir a morbidade e mortalidade materna e perinatal. Sendo assim, a avaliação de risco gestacional deve ocorrer de forma permanente e instituída em toda a consulta (BRASIL, 2013). Para isto, foi instituída como meta a avaliação de $100 \%$ das gestantes quanto ao risco gestacional. No primeiro mês de intervenção nenhuma gestante havia sido avaliada quanto ao risco gestacional. Nos meses subsequentes a avaliação foi variável, obtendo-se apenas $100 \%$ no segundo mês; no terceiro mês, 33,3\% e no quarto mês, 85,7\%. Essa dificuldade em executar essa ação deveu-se ao fato de que nem todos os profissionais comprometeram-se em 
fazer o registro da avaliação nos formulários utilizados, ficando, então, sem a avaliação de risco todas as gestantes que passaram apenas por consulta médica durante o período da intervenção. Quanto ao risco gestacional também foi instituída a meta de garantir a $100 \%$ das gestantes o diagnóstico precoce das intercorrências na gestação. Em todos os meses não se observou nenhuma gestante com intercorrência; dessa forma, o indicador não foi coletado.

\section{DISCUSSÃO}

Em relação ao atendimento pré-natal, até o início da intervenção não havia na UBS registros periódicos de acompanhamento, considerando que nem todas as gestantes eram acompanhadas e a cobertura de atendimento pré-natal estava estimada em $70 \%$. Todos os atendimentos às gestantes se restringiam, quase que exclusivamente, ao profissional médico e havia uma dificuldade em relação aos registros nos prontuários. As gestantes vinham para a consulta de pré-natal e iam embora sem ter contato com os demais profissionais da equipe. Após a realização da intervenção o atendimento às gestantes passou a ser realizado por todos os profissionais da atenção básica. Seus registros são realizados em prontuário único, ao qual todos têm acesso. Desta forma, aproximou-se do que é apontado na literatura em relação ao processo de atenção ao pré-natal realizado pela ESF, que é mais completo quando comparado ao modelo tradicional (MENDOZA-SASSI et al., 2011). Considera-se, também, que para que os demais profissionais da equipe multidisciplinar se sintam protagonistas no atendimento à gestante é necessário agir no sentido de desenvolver capacitações teóricopráticas específicas e criar protocolos que promovam a interação do trabalho médico e de enfermagem (RODRIGUES; NASCIMENTO; ARAUJO, 2011), afinal, trabalhar em equipe é muito mais do que compartilhar a mesma área física de trabalho; consiste em articular ações e os diversos saberes envolvidos no trabalho da saúde.

A intervenção dentro da UBS proporcionou ampliar a cobertura do pré-natal; melhorar a adesão ao programa; qualificar as informações nos registros e ampliar as atividades de promoção à saúde, ressaltando, assim, a melhoria da atenção prestada à população-alvo que foram as gestantes e puérperas. Proporcionou também avaliar o estado de saúde das gestantes e das puérperas, além de propiciar informações adequadas as suas condições de vida familiar e social. A abordagem do público-alvo se deu de forma mais qualificada ante a realização da visita domiciliar pelos demais membros, juntamente com o agente comunitário de saúde. Nesse sentido, a intervenção estabeleceu a necessidade de capacitação constante da equipe como um todo para melhor qualificar a assistência prestada.

A educação permanente compreende o conhecimento adquirido a partir das experiências oriundas no trabalho. Essa valorização possibilita assinalar com maior propriedade a realidade dos serviços de saúde e a expressão das fragilidades e potencialidades dos sujeitos envolvidos, impulsionando o processo de formação, a troca de experiências, a criação e a socialização de um novo saber e, por consequência, de uma nova prática (SILVA et al., 2010).

Assim, durante o início da intervenção já se observaram mudanças quando se refere à atuação dos demais profissionais da rede básica. A dentista começou a priorizar os atendimentos prestados à população-alvo, a enfermeira deu mais ênfase às visitas domiciliares com o agente comunitário de saúde. Cada profissional de saúde atuou de forma integrada. O trabalho do agente comunitário de saúde foi valorizado e enfatizado. Este, após capacitação prévia, qualificou seu trabalho pela captação precoce das gestantes para a primeira consulta, pela busca ativa para as consultas subsequentes, pelo desenvolvimento de atividades de educação em saúde tanto para as gestantes e puérperas quanto para os seus familiares, pela orientação prestada sobre os cuidados básicos de saúde, nutrição e de higiene, e pelo encaminhamento da mulher ao serviço de saúde na vigência de quaisquer alterações fisiológicas pertinentes ao período gestacional e puerperal, orientando sobre importância 
na periodicidade das consultas de pré-natal. Além disso, atuou na primeira semana pós-parto, acompanhando o processo de aleitamento, informando a mulher e seu companheiro sobre planejamento familiar.

Quanto às atividades de educação em saúde, observou-se que, no início da intervenção, esta parte da assistência pré-natal não era realizada, contudo, durante o processo e a avaliação dos indicadores, foram reavaliados e assim foi possível corrigir a forma como a assistência pré-natal estava sendo conduzida. Todas as gestantes atendidas, já no segundo mês, foram envolvidas. Diante do exposto, torna-se imprescindível o desenvolvimento de ações de educação em saúde comprometidas com os princípios de cidadania e democracia, que auxiliem as pessoas a potencializar sua autonomia e emancipação como sujeito histórico e social capaz de participar ativamente nas decisões de saúde (MONTEIRO; VIEIRA, 2010). Por este motivo reforça-se a importância da realização de projetos de intervenção junto a comunidade.

Em relação à viabilidade de incorporação da intervenção na rotina do serviço de saúde, parte-se do princípio do "querer mudar", com a participação de toda a equipe de saúde no processo de mudança. Acredita-se que a incorporação da intervenção na rotina possa oferecer uma perspectiva de avaliação contínua do serviço prestado, ao mesmo tempo contribuindo para que se possa conhecer melhor as usuárias e aumentar a qualidade da assistência de pré-natal ofertada, tendo, assim, um bom impacto administrativo e político.

Dentre as atividades que foram realizadas com total sucesso durante a intervenção, cita-se: a educação continuada da equipe; o acompanhamento de todas as gestantes e puérperas; a busca ativa das faltosas às consultas de pré-natal; a realização de todos os exames preconizados; a realização dos exames ginecológicos em todas as gestantes; as consultas de puerpério realizadas; a vacinação de todas as gestantes não apenas contra o tétano, mas também contra a hepatite B e contra a gripe; as orientações quanto aos cuidados com o recémnascido, teste do pezinho, vacinação da criança, nutrição, amamentação, anticoncepção, drogas, álcool e fumo tanto nos grupos quanto individualmente.

A atividade realizada com maior dificuldade durante a intervenção foi a visita domiciliar da enfermeira juntamente com os agentes comunitários de saúde, em razão da pouca disponibilidade do carro. Para prestar um pré-natal de qualidade, os profissionais de saúde devem estar atentos às necessidades das gestantes e nada melhor que na sua residência para qualificar a informação e assistência prestada conforme sua realidade. Tratase de um local e de um momento propício para escutá-las, oferecer informações, orientações necessárias, esclarecer dúvidas. Assim, a inserção da visita domiciliar às gestantes como rotina, feita por outro profissional que não o agente comunitário, ainda enfrenta dificuldades.

\section{CONCLUSÃO}

Com a intervenção observa-se o quão importante se faz na rotina da equipe de saúde da família a programação de estratégias e o monitoramento das atividades visando a qualificar uma ação programática. O profissional enfermeiro tem papel fundamental, pois é capaz de liderar e gerir todas as ações envolvidas.

Sabe-se que durante a gravidez muitas mudanças acontecem no corpo da mulher, fazendo com que esse período exija cuidados especiais, por isso acredita-se que este relato possa ajudar os demais serviços de atenção básica, principalmente os de enfermagem, a pensar em práticas mais eficazes para a captação das gestantes aos serviços e qualificação da assistência prestada. Entende-se também que esta experiência pode ser inspiradora para a qualificação do atendimento as outras ações programáticas na atenção básica, uma vez que a forma de abordagem pode ser reproduzida. 
Vargas; Paula L. - Casarin; Sidneia T. - Amestoy; Simone C. - Nomiyama; Seiko - Ceolin; Teila - Bandeira; Andrea G.

\section{AGRADECIMENTOS}

À coordenação e ao apoio pedagógico do curso de Especialização em Saúde da Família EAD/Ufpel, professores Anaclaudia Gastal Fassa, Elizabeth Fassa, Elaine Tomasi e Luiz Augusto Facchini.

À Secretaria Municipal de Saúde e aos profissionais da Estratégia de Saúde da Família de Vista Gaúcha/RS.

\section{REFERÊNCIAS}

ANVERSA, E. T. R. et al. Qualidade do processo da assistência pré-natal: unidades básicas de saúde e unidades de Estratégia Saúde da Família em município no Sul do Brasil. Caderno de Saúde Pública, v. 28, n. 4, p. 789-800. 2012. Disponível em: <http://www.scielosp.org/pdf/csp/v28n4/18.pdf>. Acesso em: $1^{\circ}$ dez. 2014.

BRASIL. Ministério da Saúde. Caderno da atenção básica n ${ }^{o}$ 32: atenção ao pré-natal de baixo risco. Brasília: Ministério da Saúde, 2013.

Ministério da Saúde. Política nacional de atenção básica. Brasília: Ministério da Saúde, 2012.

2002.

. Ministério da Saúde. Programa humanização do parto, humanização no pré-natal e nascimento. Brasília: Ministério da Saúde,

Portaria 1.459 de 24 de junho de 2011. Institui, no âmbito do Sistema Único de Saúde (SUS), a Rede Cegonha. Diário Oficial da União, 27 jun. 2011, Seção 1.

CESAR, J. A. et al. Assistência pré-natal nos serviços públicos e privados de saúde: estudo transversal de base populacional em Rio Grande, Rio Grande do Sul, Brasil. Caderno de Saúde Pública, v. 28, n. 11, p. 2.106-2.114. 2012. Disponível em: <http://www.scielosp.org/pdf/csp/v28n11/10.pdf >. Acesso em: 18 out. 2014.

MENDOZA-SASSI, R. A. et al. Diferenças no processo de atenção ao pré-natal entre unidades da Estratégia Saúde da Família e unidades tradicionais em um município da Região Sul do Brasil. Caderno de Saúde Pública, v. 27, n. 4, p. 787-96, 2011. Disponível em: 〈http://www.scielo.br/pdf/csp/v27n4/18.pdf>. Acesso em: $1^{\circ}$ dez. 2014.

MONTEIRO, E. M. L. M.; VIEIRA, N. F. C. Educação em saúde a partir de círculos de cultura. Revista Brasileira de Enfermagem, v. 63, n. 3, p. 397-403, 2010. Disponível em: <http://www.scielo.br/pdf/reben/v63n3/a08v63n3.pdf>. Acesso em: 1º dez. 2014.

RODRIGUES, E. M.; NASCIMENTO, R. G.; ARAUJO, A. Prenatal care protocol: actions and the easy and difficult aspects dealt by Family Health Strategy nurses. Revista da Escola de Enfermagem (USP), v. 45, n. 5, p. 1.041-1.047, 2011. Disponível em: <http://www.scielo.br/pdf/reeusp/v45n5/en_v45n5a02.pdf >. Acesso em: $1^{\circ}$ dez. 2014.

SAAVEDRA, J. S.; CESAR, J. A. Uso de diferentes critérios para avaliação da inadequação do pré-natal: um estudo de base populacional no extremo Sul do Brasil. Caderno de Saúde Pública, v. 31, n. 5, p. 1.003-1.014, 2015. Disponível em: <http://www.scielosp.org/pdf/csp/v31n5/0102-311X-csp-31-5-1003.pdf>. Acesso em: 28 ago. 2015.

SANTOS NETO, E. T. et al. O que os cartões de pré-natal das gestantes revelam sobre a assistência nos serviços do SUS da Região Metropolitana da Grande Vitória, Espírito Santo, Brasil? Caderno de Saúde Pública, v. 28, n. 9, p. 1.650-1.662, 2012. Disponível em: <http://www.scielosp.org/pdf/csp/v28n9/v28n9a05.pdf>. Acesso em: $1^{\circ}$ dez. 2014.

SILVA, L. A. A. et al. Educação permanente em saúde e no trabalho de enfermagem: perspectiva de uma práxis transformadora. Revista Gaúcha de Enfermagem, v. 31, n. 3, p. 557-561, 2010. Disponível em: 〈http://www.scielo.br/pdf/rgenf/v31n3/v31n3a21.pdf〉. Acesso em: 29 ago. 2015. 